\title{
BMJ Open Education, sex and risk of stroke: a prospective cohort study in New South Wales, Australia
}

\author{
Caroline A Jackson, ${ }^{1,2}$ Cathie L M Sudlow, ${ }^{1,3}$ Gita D Mishra ${ }^{2}$
}

To cite: Jackson CA, Sudlow CLM, Mishra GD. Education, sex and risk of stroke: a prospective cohort study in New South Wales, Australia. BMJ Open 2018;8:e024070. doi:10.1136/ bmjopen-2018-024070

- Prepublication history and additional material for this paper are available online. To view please visit the journal (http:// dx.doi.org/10.1136/bmjopen2018-024070).

Received 8 May 2018 Revised 16 July 2018 Accepted 15 August 2018

Check for updates

(C) Author(s) (or their employer(s)) 2018. Re-use permitted under CC BY-NC. No commercial re-use. See rights and permissions. Published by BMJ.

${ }^{1}$ Institute of Population Health Sciences and Informatics, University of Edinburgh, Edinburgh, UK

${ }^{2}$ School of Public Health, University of Queensland, Brisbane, Queensland, Australia

${ }^{3}$ Centre for Clinical Brain Sciences, University of Edinburgh, Edinburgh, UK

Correspondence to Dr Caroline A Jackson; caroline.jackson@ed.ac.uk

\begin{abstract}
Objective To determine whether the association between highest educational attainment and stroke differed by sex and age; and whether potential mediators of observed associations differ by sex.

Design Prospective cohort study.

Setting Population based, New South Wales, Australia. Participants 253657 stroke-free participants from the New South Wales 45 and Up Study.

Outcome measures First-ever stroke events, identified through linkage to hospital and mortality records.

Results During mean follow-up of 4.7 years, 2031 and 1528 strokes occurred among men and women, respectively. Age-standardised stroke rate was inversely associated with education level, with the absolute risk difference between the lowest and highest education group greater among women than men. In relative terms, stroke risk was slightly more pronounced in women than men when comparing low versus high education (ageadjusted HRs: $1.41,95 \% \mathrm{Cl} 1.16$ to 1.71 and $1.25,95 \% \mathrm{Cl}$ 1.07 to 1.46 , respectively), but there was no clear evidence of statistical interaction. This association persisted into older age, but attenuated. Much of the increased stroke risk was explained by modifiable lifestyle factors, in both men and women.

Conclusion Low education is associated with increased stroke risk in men and women, and may be marginally steeper in women than men. This disadvantage attenuates but persists into older age, particularly for women. Modifiable risk factors account for much of the excess risk from low education level. Public health policy and governmental decision-making should reflect the importance of education, for both men and women, for positive health throughout the life course.
\end{abstract}

\section{INTRODUCTION}

Socioeconomic disparities in health are well recognised, with lower socioeconomic position (SEP) associated with greater risk of mortality and disease, including cerebrovascular disease. ${ }^{1}$ Based on cause-specific mortality studies, absolute socioeconomic inequalities in health appear to be greater for men than women. ${ }^{2-4}$ There is, however, accumulating evidence that the SEP-cardiovascular disease relationship might actually be steeper in women than men. ${ }^{5}$ This has

\section{Strengths and limitations of this study}

A strength is the large study population and large number of outcome events, allowing stratification by sex.

- This is one of just a few studies on this topic to have included both men and women and both fatal and non-fatal stroke outcome events.

- Breadth of data enabled adjustment of many potential confounders/mediators, allowing identification of candidate mediators of the observed association.

- Limitations include the 'healthy cohort' effect which may mean findings are less generalisable to the general population.

- We could not identify non-fatal strokes for which participants were not admitted to hospital.

been investigated far less in relation to stroke, with the few, generally small, existing studies having reported conflicting findings. ${ }^{7-9}$ Furthermore, few studies have explored whether the potential underlying mechanisms of the SEP-stroke association might differ by sex.

Age differences in the SEP-stroke association have also been rarely studied. ${ }^{710}$ There are conflicting views as to whether SEP disparities in health persist into older age. Some believe that the inequality gap narrows with age, while others propose that this is an artefact of mortality selection. ${ }^{11} 12$ It is important to determine whether lower SEP poses a particular disadvantage to women's health in terms of stroke risk, and to ascertain whether such an effect, if it exists, persists over the life course in order to inform approaches to reducing health inequalities.

Valid examination of sex and age differences in SEP inequalities in disease relies on careful measurement of SEP in both sexes. Educational attainment is a particularly useful SEP measure since it is easy to measure, elicits a high response rate, is relevant regardless of age and employment status and performs well regardless of sex. ${ }^{13}$ In addition, since education is generally completed in young 
adulthood and is strongly related to parental characteristics, it also partly captures early life SEP. ${ }^{13}$ Importantly, this also minimises potential for reverse causation between SEP and health outcomes (and their risk factors).

Using data from the 45 and Up study, a large Australian prospective cohort study, we aimed to determine whether the association between highest educational attainment and stroke differed by sex and age; and whether potential mediators of observed associations differ by sex.

\section{METHODS}

\section{Study population}

We included participants from the Sax Institute's 45 and Up Study, a prospective cohort recruited between 2006 and 2009 from New South Wales (NSW), Australia, general population aged 45 years or over. Recruitment methods are described in detail elsewhere. ${ }^{14}$ Briefly, potential participants were randomly sampled from the Department of Human Services (formerly Medicare Australia) enrolment database and mailed a self-administered questionnaire and information leaflet. For this study, the cohort was linked to the NSW Admitted Patient Data Collection, the Australian Capital Territory (ACT) Admitted Patient Collection and the Australian Bureau of Statistics Death Data, with linkage performed by the Centre for Health Record Linkage. ${ }^{15}$ We excluded participants with a previous hospitalised stroke record or self-reported stroke at baseline.

\section{Education}

Education was self-reported, with participants provided with the following list and asked to provide their highest attained qualification: college/university degree; certificate/diploma/trade/apprenticeship; higher school or leaving certificate (or equivalent); school or intermediate certificate (or equivalent), typically awarded at the end of year 10 when children are aged 14, with successful completion required for the completion of the higher school certificate); or no qualifications.

\section{Stroke}

We identified incident stroke from hospital admission discharge records and mortality records and defined all strokes based on international Classification of Diseases (ICD) -10 codes (I60, I61, I63 and I64). Ischaemic stroke was defined using I63 and I64 (since the majority of 'undetermined' strokes coded as I64 will be ischaemic). ${ }^{16}$

\section{Covariates}

Definitions of all included covariates are given in online supplementary table 1 . We adjusted for demographic and other socioeconomic measures (including marital status and geographical remoteness). While area-based deprivation was available, we did not adjust for it since in univariate analyses it was not associated with stroke risk (perhaps because area is not measured at a small enough level). We also did not analyse or adjust for average household income, for two reasons. First, household income is a less reliable marker of SES, particularly among retired people (a substantial proportion of the cohort under study) because although actual household income might be low in this group, they often possess other financial assets, information on which was not collected. Second, average household income was missing in a substantial proportion of people (21\%), with higher rates of missing data among women and older people. Thus, we did not include income in our models, focusing instead on education level. We also adjusted for: psychological distress (as measured by the Kessler Psychological Distress scale ${ }^{17}$ ), a range of lifestyle factors (including fruit, vegetable and fish intake); history of disease/stroke risk factors (including physical comorbidity based on a modified Charlson Comorbidity Index ${ }^{18}$ using hospital admission data in the 5 years prior to recruitment) and among women, reproductive factors.

\section{Statistical analyses}

We performed analyses using Stata V.12. We calculated stroke rates by sex, education level and age group, age standardised to the Australian sex-specific standard population. We initially categorised age as follows: 45-59, 60-69, 70-79 and $\geq 80$ years. For the purpose of investigating interactions, we later collapsed the two lowest and two highest groups, to dichotomise age into $<70$ and $\geq 70$ years.

Overall, the frequency of missing values was less than $5 \%$ for most covariates, with the exception of geographical remoteness, which was less complete. Missing values were widely spread across participants, with $33 \%$ of men and $43 \%$ of women having missing values for at least one variable. Missing data patterns indicated that data were likely to be missing at random but not missing completely at random. We, therefore, used multiple imputation by chained equations to impute missing values of included covariates. We imputed data for men and women separately, since we had additional sex-specific covariates for women, performing 35 imputations for men and 45 imputations for women.

We used Cox regression to obtain HRs with 95\% CIs for the association between education level and stroke. We used age as the time axis, following participants from recruitment date and censoring for stroke event date, non-stroke death and end of follow-up (31 December 2012). We obtained sex-specific unadjusted HRs, before serially adjusting for groups of covariates including: other sociodemographic factors, psychological distress, lifestyle factors and disease history. Thus, we treated all covariates as common sources (confounders) in our analyses. Since some of these covariates might actually lie on a possible causal pathway between education level and stroke, we acknowledge that this assumption may not be valid and discuss the implications of this in our discussion. Our primary analysis included the multiple imputed dataset. In sensitivity analyses, we restricted our outcome to ischaemic strokes and also performed a complete case analysis. There was no clear violation of the proportional hazards assumption for education or any covariates in any analyses. 


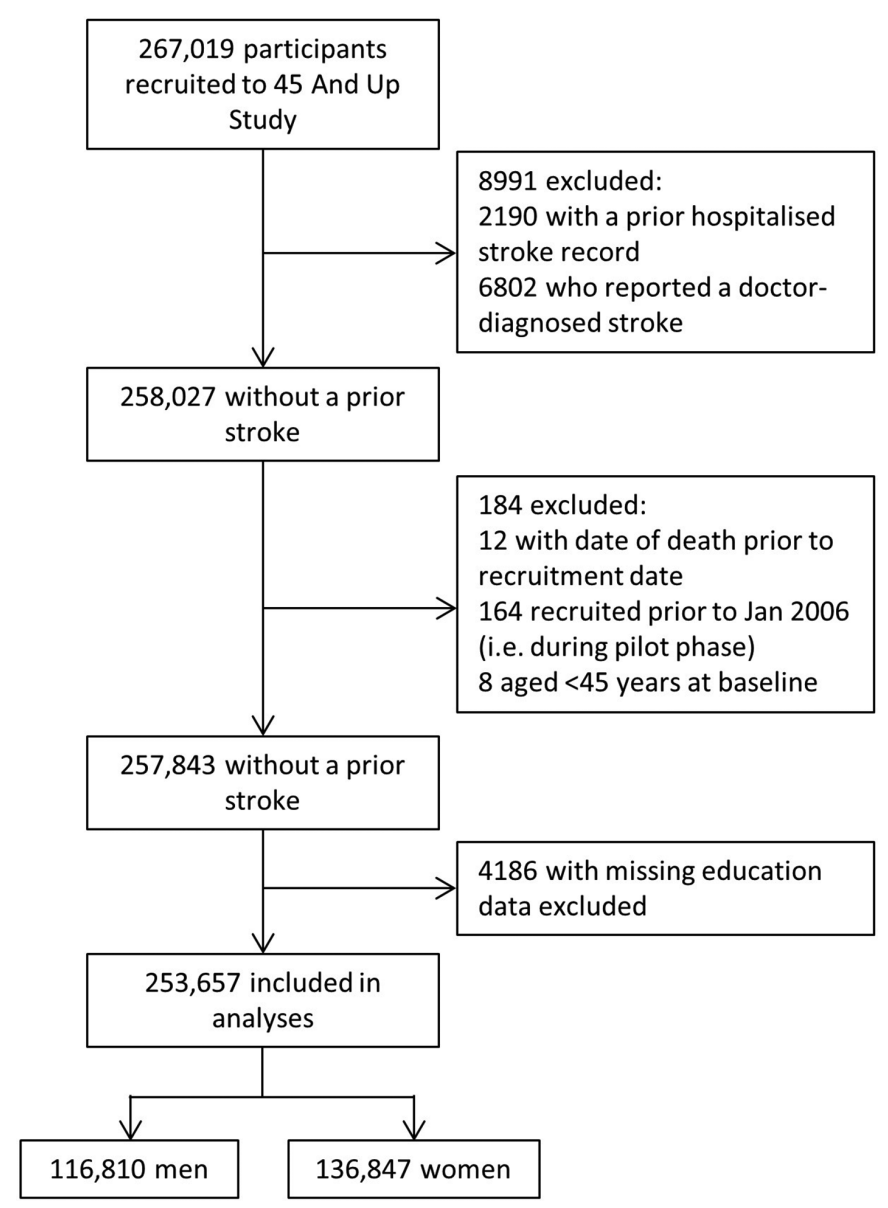

Figure 1 Flow diagram of included participants from the 45 and Up study.

We investigated effect modification by sex and age by testing for multiplicative interaction (through testing for statistical interaction in the models). Since additive interaction is more important for understanding public health, we also investigated supra-additive interaction ${ }^{19}$ between education (comparing the lowest vs highest education categories) and stroke, by calculating the relative excess risk of interaction (RERI) and synergy index with accompanying 95\% CIs. An RERI of greater/ lesser than 0 and a synergy index of greater/lesser than 1 indicate that the combined effects of each exposure is more or less than expected from adding the individual effects.

Results are reported in accordance with the Strengthening the Reporting of Observational Studies statement. $^{20}$

\section{Patient and public involvement}

We did not include patient or public involvement in the conduct of the present study.

\section{RESULTS}

Among 257843 participants eligible for inclusion, we excluded $4186(1.6 \%)$ with missing information on education, ultimately including 253657 participants (figure 1). Compared with included participants, excluded participants were older and more likely to be: female; from areas of higher deprivation and less healthy (online supplementary table 2).

We included 116810 men and 136847 women (mean \pm SD age in years $63.3 \pm 11.0$ and $61.4 \pm 10.9$, respectively). Sex-specific cross-tabulations of characteristics by education level are given in online supplementary tables 3 and 4. Distribution of education level differed by sex and age. The proportion with a college or university qualification was slightly higher in men than women (25.6\% vs $22.2 \%)$ and the proportion with no qualifications slightly higher in women than men $(12.4 \%$ vs $10.7 \%)$. The proportion with no qualifications or a school/intermediate certificate was higher among older age groups (and was greater in women than men), whereas the proportion with a college/university degree was higher among younger age groups (with far less disparity between women and men). Lower educational status was associated with poorer lifestyle behaviour and clinical stroke risk factors, with similar patterns observed in men and women. Similarly, most characteristics were associated with stroke risk (online supplementary table 5 ).

\section{Absolute and relative stroke risk by education, sex and age} Mean follow-up was $4.70( \pm$ SD 0.98$)$ years. Among men, 2031 strokes (1696 ischaemic) occurred during 545543 person-years of follow-up and among women 1528 strokes (1225 ischaemic) occurred during 644362 person-years.

The pattern of absolute stroke risk was not linear with education level. For both men and women, absolute stroke rates were lowest in the group with highest educational attainment. The stroke rates for each of the other education categories were higher, but generally similar to each other, particularly for men. Among women, the stroke rates in the three middle categories of educational attainment are very similar, with the rate in the group with no qualifications even higher (figure 2A and table 1). In contrast, among men, in comparison to the highest education category, stroke rates for each of the other education categories were higher, but to a similar extent, with CIs for estimates overlapping. If anything, the stroke rate in those with no qualifications was slightly lower than in those with a trade/apprenticeship or school certificate (figure 2C and online supplementary table 6). Among those with no qualifications, the stroke rate was slightly greater in women than men and the absolute risk difference between lowest and highest education categories was greater in women than men (table 1). After stratifying by age group, a similar pattern was observed for those aged under 70 years (figure 2B and online supplementary figure 1) and, among women, for those aged 70 years or over.

In relative terms, having no qualifications was significantly associated with increased stroke risk in men and women, but was slightly more pronounced in women than men (age-adjusted HRs 1.41, 95\% CI 1.16 to 1.71 and $1.25,95 \%$ CI 1.07 to 1.46 , respectively; table 2 ). 


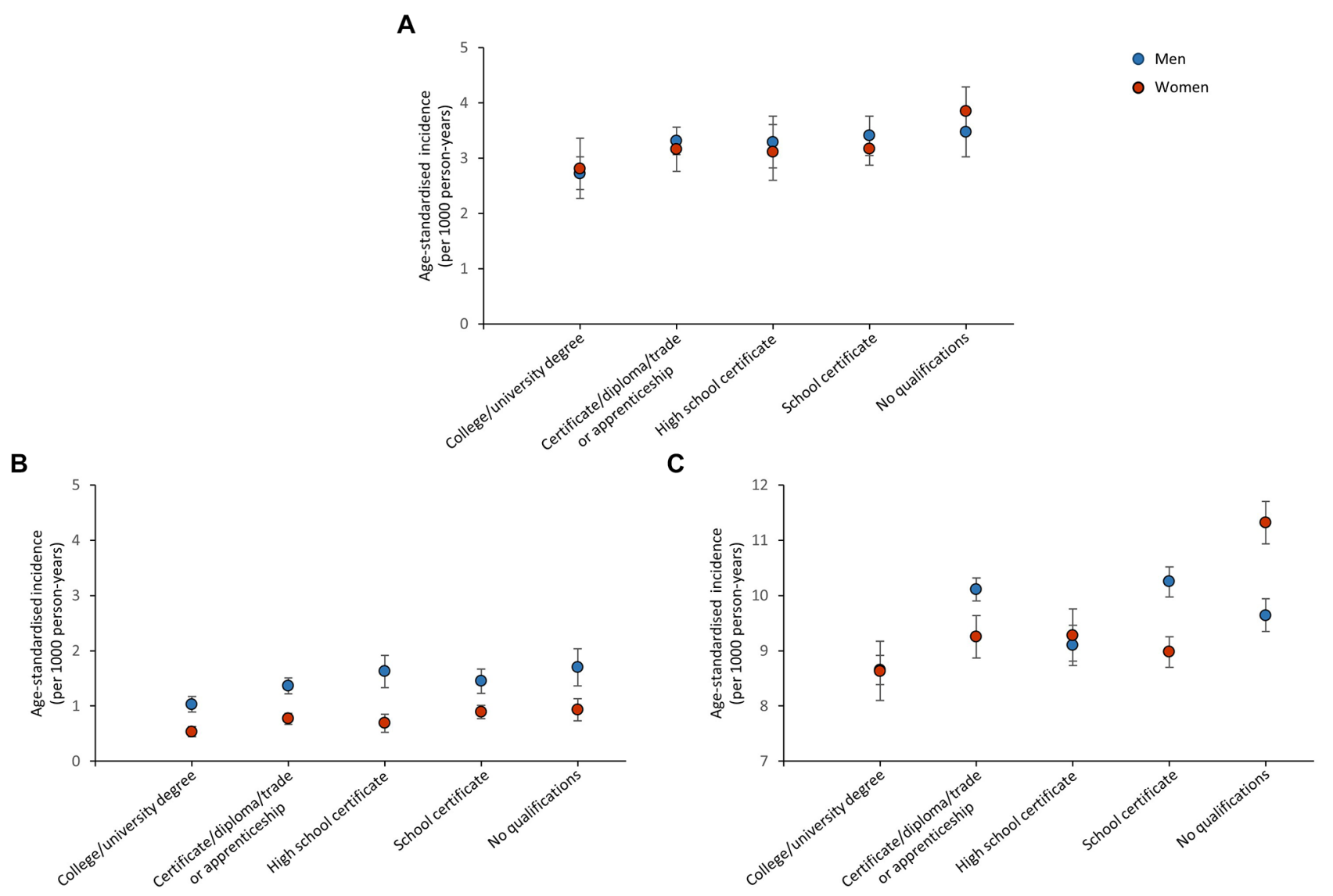

Figure 2 Absolute stroke risk by education level among men and women, showing age-standardised stroke incidence (per 1000 person-years) for (A) all ages; (B) age 45-69 years and (C) age 70 years or over (at baseline).

Among women, a similar magnitude of effect was observed for the middle three categories of education level versus the highest level, each of which was associated with about a $20 \%$ increased risk of stroke (table 2 , model 1). This pattern persisted when stratifying by age group, although effect estimates were larger in those aged 45-69 than 70 years or over for both sexes. The association between education and stroke among those aged 45-69 was slightly stronger in women than men (HR lowest vs highest education level: $1.73,95 \% \mathrm{CI}$ 1.20 to 2.49 and $1.58,95 \%$ CI 1.19 to 2.10 , respectively).
The association between education and stroke was somewhat weaker in men aged 70 years or over, but persisted among women in this age group, with having no qualifications associated with a $21 \%$ increased risk of stroke (HR 1.21, 95\% CI 0.96 to 1.52), although this was not statistically significant (online supplementary table 6). However, having only a school certificate was statistically significantly associated with increased stroke risk in men aged 70 or over (HR 1.21, 95\% CI 1.02 to 1.44). Similar associations were found when we restricted our analyses to ischaemic strokes only.

Table 1 Sex-specific age-standardised incidence rates (per 1000 person-years) for stroke, by education level

\begin{tabular}{|c|c|c|c|c|c|c|}
\hline \multirow[b]{2}{*}{ Education level } & \multicolumn{3}{|c|}{ Men $(n=116810)$} & \multicolumn{3}{|c|}{ Women $(n=136847)$} \\
\hline & $\begin{array}{l}\text { Person- } \\
\text { years }\end{array}$ & $\begin{array}{l}\text { Stroke } \\
\text { events, N }\end{array}$ & $\begin{array}{l}\text { Incidence rate, per } \\
1000 \text { person-years* } \\
(95 \% \mathrm{Cl})\end{array}$ & $\begin{array}{l}\text { Person- } \\
\text { years }\end{array}$ & $\begin{array}{l}\text { Stroke } \\
\text { events, N }\end{array}$ & $\begin{array}{l}\text { Incidence rate, per } \\
1000 \text { person-years } \\
(95 \% \mathrm{Cl})\end{array}$ \\
\hline College/university degree & 141248 & 352 & 2.72 (2.43 to 3.02 ) & 143774 & 160 & 2.81 (2.27 to 3.36$)$ \\
\hline $\begin{array}{l}\text { Certificate/diploma/trade or } \\
\text { apprenticeship }\end{array}$ & 210375 & 784 & 3.31 (3.06 to 3.56$)$ & 174968 & 333 & 3.16 (2.76 to 3.56$)$ \\
\hline $\begin{array}{l}\text { School/intermediate } \\
\text { certificate }\end{array}$ & 82961 & 398 & 3.41 (3.05 to 3.76$)$ & 181673 & 524 & 3.17 (2.87 to 3.46$)$ \\
\hline No qualifications & 57496 & 297 & 3.47 (3.02 to 3.92$)$ & 79029 & 348 & 3.85 (3.42 to 4.29$)$ \\
\hline
\end{tabular}

${ }^{*}$ Age standardised to the Australian sex-specific standard population. 
Table 2 Serially adjusted HRs for the association between education level and stroke, stratified by sex

Education level

\begin{tabular}{|c|c|c|c|c|c|}
\hline & $\begin{array}{l}\text { College/ } \\
\text { university degree }\end{array}$ & $\begin{array}{l}\text { Certificate/diploma/ } \\
\text { trade/ } \\
\text { apprenticeship }\end{array}$ & $\begin{array}{l}\text { Higher school } \\
\text { certificate }\end{array}$ & $\begin{array}{l}\text { School/intermediate } \\
\text { certificate }\end{array}$ & No qualifications \\
\hline & Reference & HR $(95 \% \mathrm{Cl})$ & HR $(95 \% \mathrm{Cl})$ & HR (95\% Cl) & HR (95\% Cl) \\
\hline \multicolumn{6}{|c|}{ Men (2031 strokes among $n=116810$ ) } \\
\hline Model $1^{*}$ & 1.00 & $1.20(1.06$ to 1.37$)$ & $1.23(1.04$ to 1.47$)$ & $1.31(1.13$ to 1.51$)$ & $1.25(1.07$ to 1.46$)$ \\
\hline Model $4 \S$ & 1.00 & 1.17 (1.03 to 1.33$)$ & 1.17 (0.98 to 1.39$)$ & 1.23 (1.06 to 1.42$)$ & $1.12(0.96$ to 1.32$)$ \\
\hline Model 5ף & 1.00 & 1.16 (1.02 to 1.32$)$ & $1.16(0.97$ to 1.38$)$ & $1.21(1.05$ to 1.40$)$ & $1.10(0.94$ to 1.30$)$ \\
\hline \multicolumn{6}{|c|}{ Women (1528 strokes among $n=136847$ ) } \\
\hline Model $1^{*}$ & 1.00 & $1.21(1.00$ to 1.46$)$ & $1.21(0.97$ to 1.51$)$ & $1.23(1.03$ to 1.47$)$ & $1.41(1.16$ to 1.71$)$ \\
\hline Model $5^{\Uparrow}$ & 1.00 & $1.16(0.96$ to 1.40$)$ & $1.17(0.93$ to 1.53$)$ & $1.15(0.96$ to 1.38$)$ & $1.22(1.00$ to 1.49$)$ \\
\hline Model $6^{\star \star}$ & 1.00 & $1.12(0.90$ to 1.38$)$ & 1.09 (0.85 to 1.40$)$ & $1.15(0.94$ to 1.41$)$ & $1.21(0.97$ to 1.51$)$ \\
\hline
\end{tabular}

${ }^{*}$ Adjusted for age.

†Model 1+ marital status and remoteness.

$\ddagger$ Model 2+ psychological distress.

§Model 3+ smoking, alcohol intake, body mass index, physical activity, fruit and vegetable intake, fish consumption.

ףModel 4+ history of hypertension, heart disease, diabetes and treatment for raised cholesterol, Charlson Comorbidity Index and family history of stroke/heart disease.

${ }^{* *}$ In women, model 4+ oral contraceptive use, hormone replacement therapy use and menopausal status.

\section{Sex and age interactions with education}

Although the effect of education on stroke risk appeared to be slightly greater among women than men, there was no evidence of statistical interaction on either the multiplicative or additive scale. Although the RERI and synergy index were less than 0 and 1 , respectively, CIs did not exclude the possibility of no interaction (online supplementary table 7). Similarly, there was no clear evidence of statistical interaction between age and education for men or women (online supplementary table 7 ).

\section{Fully adjusted education-stroke associations}

Adjusting for confounding by marital status and geographical remoteness had little effect on the associations (table 2). Following additional adjustment for behavioural factors and disease history, which could confound and/or possibly mediate a potentially causal association between education level and stroke risk, the magnitude of effect was attenuated and, for almost all education categories, was no longer statistically significant (fully adjusted HRs for lowest vs highest education level in men and women: $1.10,95 \%$ CI 0.94 to 1.30 and $1.21,95 \%$ CI 0.97 to 1.51 , respectively; table 2). While the same pattern of association was observed in the complete case analysis, when compared with the analysis of the imputed dataset, the magnitude of effect was slightly greater for all education categories (online supplementary table 8 ).

\section{DISCUSSION}

We found an inverse, although non-linear, association between education level and stroke risk in both men and women, which was slightly more pronounced in women than men. The association weakened somewhat in older ages for men and, to a lesser extent, for women. Modifiable lifestyle factors explained much of the increased stroke risk in both sexes.

Our study benefits from the key strengths. We included a very large stroke-free study population, among which a large number of strokes occurred, providing sufficient power to stratify by sex. The breadth of data collected allowed us to adjust for a wide range of potential confounders/mediators, including those less commonly adjusted for in previous studies, to identify candidate mediators through which education level might affect stroke risk. There are, however, some limitations. First, the participation rate in the 45 and Up Study is about $18 \%$ and given the 'healthy cohort effect', it is unlikely to be representative of the general NSW population aged 45 and over. ${ }^{14}$ However, the cohort is heterogeneous across collected variables. Thus, while people with a low education level may well be under-represented in this cohort, given the cohort size and heterogeneity, this is unlikely to have had an effect on internal comparisons of exposure and outcome. ${ }^{14}$ Second, it is important to recognise that the meaning of education differs by birth cohort. The 
consequences of having no high school education may differ among those born in the 1950s versus the 1920s, for example. However, we did take this into account by examining the association between education and stroke risk within different age groups. Third, we were unable to identify non-fatal strokes for which people were not admitted to hospital (estimated to be about $15 \%$ of all strokes, but likely higher among older people ${ }^{21}$ ) or strokes that occurred outside NSW and the ACT (which will have been few in number). Fourth, misclassification of stroke diagnosis may have occurred within hospital and mortality records. However, a recent systematic review of the accuracy of hospital and mortality records suggests that the use of appropriately selected, stroke-specific codes (rather than broad cerebrovascular disease codes) yields positive predictive values of greater than $70 \%$ in most studies and greater than $90 \%$ in some studies. ${ }^{16}$ Finally, since we do not have time-varying information on covariates, we cannot be certain that all covariates are indeed confounders and not mediators in the relationship between education and stroke. We may therefore have overadjusted our analyses by including possible mediators, thereby underestimating the association between education and stroke.

Our finding that education level is associated with stroke risk is consistent with the findings from many existing studies. ${ }^{792-26}$ We did not however observe an incremental increase in stroke risk with decreasing education level. This is in keeping with some other studies where education was classified into more than three groups and where a non-linear pattern of association with stroke was observed. ${ }^{724}$ This may reflect a true non-linear relationship between education level and stroke in some settings. In the present study, the distribution of other stroke risk factors, such as history of diabetes, hypertension and key lifestyle factors was very similar among those with a diploma/trade/apprenticeship, higher school certificate or school/intermediate certificate. This might help explain why similar stroke rates were seen in these groups. Also, among men, the similarity in stroke risk between each of these education groups and the group with no qualifications is intriguing. As discussed below, this might reflect that men are able to compensate for having no qualifications to a greater extent than women.

Our study makes an important contribution to the small body of existing literature on SEP-sex interactions on stroke risk and indeed circulatory disease in general. A recent systematic review and meta-analysis concluded that there are sex differences in the relationship between education and coronary heart disease, but not stroke. ${ }^{5}$ However, the authors included studies of stroke mortality and not just stroke incidence. Results of the latter studies tended to suggest greater education-stroke inequalities in men than women. They also included studies from low-income and middle-income settings, where the SEP-stroke gradient itself might differ from high-income settings.

Findings from the very few studies that have explored interactions by age and sex on stroke risk are mixed. One reported no difference by sex, ${ }^{27}$ whereas a second found an association between low education and increased stroke risk among men but not women. ${ }^{23}$ Consistent with our findings, two studies found the education-stroke association was weaker ${ }^{8}$ or absent ${ }^{9}$ in men.

There is biological plausibility for a different SEP-stroke association among women compared with men. Sex differences in the association between household income and atherosclerotic processes in adolescence were observed in one study, which were partially explained by a stronger income-adiposity association in females. ${ }^{28}$ Similarly, the associations between SEP and carotid atherosclerosis in mid-age have been reported to be greater among men than women. ${ }^{29}$ Furthermore, based on the theory of resource substitution (which states that resources can substitute for one another), education may be more important to women's health compared with men's because they have fewer socioeconomic resources of other kinds (such as income, power, authority and wealth) to draw on. ${ }^{30}$ In our study, income was lower among women than men across educational categories, but there was substantial missing data on income, especially among women, which precluded more detailed analyses. While we were able to adjust for marital status, we were unable to adjust for spousal educational status, which is also thought to play a role in individuals' health. ${ }^{31}$

We also demonstrated that the adverse effect of low education on stroke risk attenuated but did persist in older age groups. The slightly weaker association between education and stroke among elderly men may reflect mortality selection, ${ }^{12}$ since educational disparities in mortality are greater among men than women. Our findings therefore support the view that socioeconomic inequalities in health persist into older age. ${ }^{11}$ Two previous studies on education and stroke risk stratified by age group, but they did not stratify by sex. In one, low education was associated with increased stroke risk in those aged 65-74 years, but a decreased risk in those aged 75 years or over. ${ }^{7}$ In contrast, the other study found no association among those aged $65-74$ years, but a trend towards reduced risk in those with high versus low education aged 50-64 years. ${ }^{10}$ Two studies of women only, with mean age less than 50 years, reported a magnitude of effect comparable to that among women aged less than 70 years in our study. ${ }^{2532}$

Our results suggest that lifestyle factors predominantly account for the observed increased stroke risk but that psychological distress and disease history are also important, perhaps more so for women than men. It is difficult to compare our sex-specific findings to similar studies of education and stroke, given that so few studies stratified by sex. A formal mediation study, using a path analysis approach, suggested that behavioural factors account for much of the education-cardiovascular disease gradient, ${ }^{33}$ which concurs with our findings. There is evidence that, when stratifying by sex, lifestyle behaviours may account for all of the education-cardiovascular association in men, but not women. ${ }^{34}$ Our findings support this to some 
extent in that the slight excess stroke risk seen in women does persist after full adjustment for confounders/potential mediators. In addition, previous studies have posited a possible role for psychosocial factors as partial mediators of the association between education and stroke ${ }^{35}$ and cardiovascular disease ${ }^{36}$ in women. In line with this, adjustment for psychological distress in our study notably attenuated the effect estimates for women, but not men.

Since this is one of the few studies to date to examine the association between education and stroke risk by sex, within the same study population, further research is needed to confirm or refute the possibility of steeper socioeconomic-stroke disparities in women compared with men. Further investigation is also needed to shed more detailed understanding on the underlying mechanisms of the relationship between socioeconomic status and stroke risk and determine where these differ between men and women. Mediation analyses to unpick these mechanisms should stratify by sex and include non-conventional risk factors (such as psychosocial factors) as well as traditional cardiovascular risk factors. Such studies will inform tailored prevention strategies aimed at reducing health inequalities. Meanwhile, ongoing public health investment is needed to facilitate healthy lifestyle behaviour and reduce uptake of poor health behaviours, particularly in vulnerable socioeconomic groups.

\section{Conclusion}

Our study suggests that the education-stroke relationship is present in both men and women, but may be marginally stronger for women than men, with low education a disadvantage to women throughout the life course. The critical importance of education, of both men and women, for positive health throughout the life course should be reflected in public health and educational policy and governmental decision-making.

Acknowledgements This research was completed using data collected through the 45 and Up Study (www.saxinstitute.org.au). The 45 and Up Study is managed by the Sax Institute in collaboration with major partner Cancer Council NSW; and partners: the National Heart Foundation of Australia (NSW Division); NSW Ministry of Health; NSW Government Family and Community Services-Ageing, Carers and the Disability Council NSW; and the Australian Red Cross Blood Service. We thank the many thousands of people participating in the 45 and Up Study.

Contributors CAJ designed the study, CLMS and GDM contributed to the analytical strategy and interpretation of the results. CAJ drafted the manuscript and CLMS and GDM commented on and approved the final draft.

Funding This work was supported by a University of Queensland Early Career Researcher Grant awarded to CAJ (grant number 2013002357).

Competing interests None declared.

Patient consent Not required.

Ethics approval The conduct of the 45 and Up Study was approved by the University of NSW Human Research Ethics Committee. Ethical approval for the present study was obtained from the NSW Population and Health Services Research Ethics Committee, the ACT Health Human Research Ethics Committee and the University of Queensland Institutional Human Research Ethics Committee

Provenance and peer review Not commissioned; externally peer reviewed.

Data sharing statement The 45 And Up study data are accessible to any bona fide researcher who has a scientifically sound and feasible research proposal, has ethics approval for the study and can cover the licence fees and costs incurred by accessing the data through the Secure Unified Research Environment provided by the New South Wales Sax Institute (https://www.saxinstitute.org.au/our-work/45up-study/for-researchers/). Researchers accessing the data do not retain copies of the dataset and are not able to share these data with anyone else.

Open access This is an open access article distributed in accordance with the Creative Commons Attribution Non Commercial (CC BY-NC 4.0) license, which permits others to distribute, remix, adapt, build upon this work non-commercially, and license their derivative works on different terms, provided the original work is properly cited, appropriate credit is given, any changes made indicated, and the use is non-commercial. See: http://creativecommons.org/licenses/by-nc/4.0/.

\section{REFERENCES}

1. Marshall IJ, Wang Y, Crichton S, et al. The effects of socioeconomic status on stroke risk and outcomes. Lancet Neurol 2015;14:1206-18.

2. Huisman M, Kunst AE, Bopp M, et al. Educational inequalities in cause-specific mortality in middle-aged and older men and women in eight western European populations. Lancet 2005;365:493-500.

3. Mackenbach JP, Hu Y, Artnik B, et al. Trends in inequalities in mortality amenable to health care in 17 European Countries. Health Aff 2017;36:1110-8.

4. Mustard CA, Etches J. Gender differences in socioeconomic inequality in mortality. J Epidemiol Community Health 2003;57:974-80.

5. Backholer K, Peters SAE, Bots SH, et al. Sex differences in the relationship between socioeconomic status and cardiovascular disease: a systematic review and meta-analysis. J Epidemiol Community Health 2017;71:550-7.

6. Ernstsen L, Bjerkeset O, Krokstad S. Educational inequalities in ischaemic heart disease mortality in 44,000 Norwegian women and men: the influence of psychosocial and behavioural factors. The HUNT Study. Scand J Public Health 2010;38:678-85.

7. Avendano M, Kawachi I, Van Lenthe F, et al. Socioeconomic status and stroke incidence in the US elderly: the role of risk factors in the EPESE study. Stroke 2006;37:1368-73.

8. Gillum RF, Mussolino ME. Education, poverty, and stroke incidence in whites and blacks: the NHANES I Epidemiologic Follow-up Study. $J$ Clin Epidemiol 2003;56:188-95.

9. Veronesi G, Ferrario MM, Chambless LE, et al. Gender differences in the association between education and the incidence of cardiovascular events in Northern Italy. Eur $\mathrm{J}$ Public Health 2011;21:762-7.

10. Avendano M, Glymour MM. Stroke disparities in older Americans: is wealth a more powerful indicator of risk than income and education? Stroke 2008;39:1533-40.

11. Benzeval M, Green MJ, Leyland AH. Do social inequalities in health widen or converge with age? Longitudinal evidence from three cohorts in the West of Scotland. BMC Public Health 2011;11:947.

12. Dupre ME. Educational differences in age-related patterns of disease: reconsidering the cumulative disadvantage and age-asleveler hypotheses. $J$ Health Soc Behav 2007;48:1-15.

13. Galobardes B, Shaw M, Lawlor DA, et al. Indicators of socioeconomic position (part 1). J Epidemiol Community Health 2006;60:7-12.

14. Banks E, Redman S, Jorm L, et al. Cohort profile: the 45 and up study. Int J Epidemiol 2008;37:941-7.

15. Centre for Health Record Linkage. http://www.cherel.org.au/datadictionaries\#section6 (accessed 1 Mar 2017).

16. Woodfield R, Grant I, Sudlow CL. UK Biobank Stroke Outcomes GroupUK Biobank Follow-Up and Outcomes Working Group. Accuracy of electronic health record data for identifying stroke cases in large-scale epidemiological studies: a systematic review from the UK biobank stroke outcomes group. PLoS One 2015;10:e0140533.

17. Kessler RC, Andrews G, Colpe LJ, et al. Short screening scales to monitor population prevalences and trends in non-specific psychological distress. Psychol Med 2002;32:959-76.

18. Romano PS, Roos LL, Jollis JG. Adapting a clinical comorbidity index for use with ICD-9-CM administrative data: differing perspectives. J Clin Epidemiol 1993;46:1075-9.

19. Andersson T, Alfredsson L, Källberg $\mathrm{H}$, et al. Calculating measures of biological interaction. Eur J Epidemiol 2005;20:575-9.

20. Vandenbroucke JP, von Elm E, Altman DG, et al. Strengthening the Reporting of Observational Studies in Epidemiology (STROBE): explanation and elaboration. PLoS Med 2007;4:e297.

21. Anderson CS, Jamrozik KD, Burvill PW, et al. Ascertaining the true incidence of stroke: experience from the Perth Community Stroke Study, 1989-1990. Med J Aust 1993;158:80-4. 
22. Andersen KK, Steding-Jessen M, Dalton SO, et al. Socioeconomic position and incidence of ischemic stroke in Denmark 2003-2012. A nationwide hospital-based study. J Am Heart Assoc 2014;3:e000762.

23. Avendano M, Boshuizen HC, Schellevis FG, et al. Disparities in stroke preventive care in general practice did not explain socioeconomic disparities in stroke. J Clin Epidemiol 2006;59:1285-94.

24. Jackson CA, Jones M, Mishra GD. Educational and homeownership inequalities in stroke incidence: a population-based longitudinal study of mid-aged women. Eur J Public Health 2014;24:231-6.

25. Kuper H, Adami HO, Theorell T, et al. The socioeconomic gradient in the incidence of stroke: a prospective study in middle-aged women in Sweden. Stroke 2007;38:27-33.

26. Liu L, Xue F, Ma J, et al. Social position and chronic conditions across the life span and risk of stroke: a life course epidemiological analysis of 22,847 American adults in ages over 50. Int J Stroke 2013;8(Suppl A100):50-5.

27. Honjo K, Tsutsumi A, Kayaba K. Jichi Medical School Cohort Study Group. Socioeconomic indicators and cardiovascular disease incidence among Japanese community residents: the Jichi Medical School Cohort Study. Int J Behav Med 2010;17:58-66.

28. Murasko JE. Male-female differences in the association between socioeconomic status and atherosclerotic risk in adolescents. Soc Sci Med 2008:67:1889-97.

29. Rosvall M, Ostergren PO, Hedblad B, et al. Occupational status, educational level, and the prevalence of carotid atherosclerosis in a general population sample of middle-aged Swedish men and women: results from the Malmö Diet and Cancer Study. Am J Epidemiol 2000;152:334-46.

30. Ross CE, Masters RK, Hummer RA. Education and the gender gaps in health and mortality. Demography 2012;49:1157-83.

31. Brown DC, Hummer RA, Hayward MD. The importance of spousal education for the self-rated health of married adults in the United States. Popul Res Policy Rev 2014;33:127-51.

32. Honjo $\mathrm{K}$, Iso $\mathrm{H}$, Inoue $\mathrm{M}$, et al. Education, social roles, and the risk of cardiovascular disease among middle-aged Japanese women: the JPHC Study Cohort I. Stroke 2008;39:2886-90.

33. Kershaw KN, Droomers M, Robinson WR, et al. Quantifying the contributions of behavioral and biological risk factors to socioeconomic disparities in coronary heart disease incidence: the MORGEN study. Eur J Epidemiol 2013;28:807-14.

34. Ricceri F, Sacerdote C, Giraudo MT, et al. The association between educational level and cardiovascular and cerebrovascular diseases within the EPICOR study: new evidence for an old inequality problem. PLoS One 2016;11:e0164130.

35. Jackson CA, Mishra GD. Depression and risk of stroke in midaged women: a prospective longitudinal study. Stroke 2013;44:1555-60.

36. Thurston RC, Kubzansky LD, Kawachi I, et al. Is the association between socioeconomic position and coronary heart disease stronger in women than in men? Am J Epidemiol 2005;162:57-65. 